\title{
Revista

\section{LÍNGUA BRASILEIRA DE SINAIS EM CONTEXTO: INCLUSÃO DOS INDIVÍDUOS SURDOS}

\author{
DOI:10.5965/19843178912014034 \\ http://dx.doi.org/10.5965/19843178912014034
}

\author{
José Marcos Rosendo de Souza \\ Clara Dulce Pereira Marques² \\ Maria Lúcia Pessoa Sampaio ${ }^{3}$
}

\section{RESUMO}

É notória a importância que a Língua Brasileira de Sinais adquire no universo dos surdos e, como um dos elementos constitutivos desse valor, podemos apontar a concretização da comunicação antes impossibilitada em decorrência da surdez. A presente pesquisa tem por objetivos traçar um escorço histórico das Línguas de Sinais a partir da criação de metodologias educacionais que possibilitaram o desenvolvimento cognitivo dos indivíduos surdos, isto é, conhecer o contexto histórico das metodologias educacionais que foram e podem ser aplicadas ao ensino dos surdos. Nessa perspectiva, o presente trabalho justifica-se pelo fato de que há a necessidade de se discutir a inclusão desses indivíduos através de sua língua materna, pois socialmente eles sempre foram excluídos da sociedade. Assim, uma pesquisa direcionada ao interesse de conhecer a língua desses indivíduos enquanto ferramenta de inclusão possibilita aprofundar a produção científica nesta área do conhecimento. Para este artigo serão utilizadas obras de autores como

Quadros e Karnopp (2004), Magalhães (2011), Salles (2004), dentre outros, que contribuíram significativamente para temática, sendo assim classificada, como pesquisa bibliográfica. Como resultados, este estudo buscará apresentar a Língua de Sinais como a possibilidade mais viável para inclusão dos surdos no contexto social e escolar, tendo em

\footnotetext{
${ }^{1}$ Mestrando na Universidade do Estado do Rio Grande do Norte.

${ }^{2}$ Mestranda na Universidade do Estado do Rio Grande do Norte.

${ }^{3}$ Doutorado em Educação.
} 


\title{
Revista

vista que é através dela que os surdos podem desenvolver a comunicação, e também, estarem incluídos no processo de ensino/aprendizagem efetivamente.

Palavras-chave: Língua Brasileira de Sinais. Inclusão. Ensino. Surdos.

\section{BRAZILIAN SIGN LANGUAGE IN CONTEXT: INCLUSION OF DEAF INDIVIDUALS}

\begin{abstract}
It is noticeable the importance of the Brazilian Sign Language acquires in the universe of deaf and, as one of the constituent elements of this value, we can point to the achievement of communication, impossible before due to deafness. This research aims to draw a

historical foreshortening of Sign Language from the creation of educational methodologies that allowed the cognitive development of deaf individuals, that is, knowing the historical context of educational methodologies that have been and can be applied to the teaching of the deaf. In this perspective, this work is justified by the fact that there is a need to discuss the inclusion of these individuals through their native language because they have always been socially excluded from society. Thus, a research directed to the interest of knowing the language of these individuals as inclusion tool enables furthering scientific knowledge production in this area. For this article, works of authors will be used as Quadros and Karnopp (2004), Magalhães (2011), Salles (2004), and others, who have contributed significantly to theme; therefore it is classified as a bibliographical research. As a result, this study will seek to provide sign language as the most viable option for inclusion of deaf people in the social context and school, considering that it is through it that the deaf can develop communication and are also included in the teaching/learning process effectively.
\end{abstract}

Keywords: Brazilian Sign Language. Inclusion. Education. Deaf. 


\section{Revista

\section{INTRODUÇÃO}

As relações humanas são pautadas principalmente na comunicação, isto é, os indivíduos procuram em seus pares semelhantes a reciprocidade comunicativa, para que se possam firmar enquanto indivíduos plenamente dotados dessa competência: a comunicação. E ainda vale salientar que ela está presente em todas as esferas sóciocomunicativas, partindo desde o cotidiano familiar até a esfera escolar.

Nessa perspectiva, o contexto escolar apresenta-se como um ambiente propício para o desenvolvimento comunicativo dos indivíduos, principalmente, nas relações construídas entre os pares: aluno/aluno e professor/aluno, ou seja, há uma interação constante entre os indivíduos. É notório ratificar que, quando se faz referência às relações comunicativas entre alunos/professores, nesse grupo estariam todos os alunos, inclusive os Surdos.

Assim, é perceptível que essa interação desenvolvida no contexto escolar deve estar pautada nos parâmetros de inclusão dos indivíduos Surdos, ou seja, a escola hoje é responsável por proporcionar a esses indivíduos condições necessárias para o seu desenvolvimento. E, isso ocorrerá somente através da Língua materna dos Surdos: a Língua de Sinais ${ }^{4}$.

Desse modo, o presente artigo tem por objetivo mostrar essa Língua como ferramenta de inclusão dos indivíduos surdos. E, podendo ser justificada, pelo fato de ser necessário discutir sobre a inclusão desses indivíduos proporcionada pela sua língua materna. Para que possa ser consolidada, optou-se por uma pesquisa bibliográfica, tendo em vista que foram utilizados um aparato bibliográfico de autores como: Quadros e Karnopp (2004), Magalhães (2011), Salles (2004) e dentre outros.

\footnotetext{
${ }^{4}$ Em relação a isso, vale salientar que cada país possui uma Língua de Sinais, ou seja, enquanto língua, ela não é universal; cada país possui sua própria Língua de Sinais.
} 


\section{Revista

\section{PANORAMA HISTÓRICO DAS LÍNGUAS DE SINAIS}

\subsection{Indícios: contexto europeu}

Enquanto instituição social, a língua se faz presente nas mais diferentes situações comunicativas, desde as relações triviais dos indivíduos, até as interações mais complexas, ou seja, pode-se afirmar que ela é uma constante no cotidiano de todo sujeito. Sendo assim, vale salientar que aquela está presente na sociedade desde o surgimento do homo sapiens ao tempo presente do homem.

Diante do exposto, e corroborando esta afirmação, de que a língua se transforma a cada nova produção social, isto é, a cada ato comunicativo, Bakhtin (2009, p. 84) afirma que a língua não se limita a repetição de uma norma, mas, “[...] sim uma renovação constante, a individualização das formas em enunciação estilisticamente únicas e reiteráveis.”.

Isto é, a cada novo ato comunicativo a língua se renova, transformando-se em novas possibilidades de utilização, logicamente, vale salientar que isso, também, ocorre em detrimento do contexto social do indivíduo, ou seja, o contexto, nesse caso, pode ser compreendido como determinante para o desenvolvimento da competência comunicativa. E, desse modo, a língua evolui conforme o desenvolvimento comunicativo dos falantes, e esse critério evolutivo pode ser atribuído a toda língua natural. De igual forma, também se atribui às Línguas de Sinais, tendo em vista que elas são naturais às comunidades dos falantes surdos.

Assim, é perceptível que todo falante reúne habilidades únicas para construir inúmeras possibilidades para se comunicar na interação. Então, pode-se afirmar que todo falante é linguisticamente criativo, conforme corrobora Martelotta et al (2011, p. 128) ao afirmar que todos os falantes são criativos independentemente de seu grau de instrução, 


\section{Revista

pois “[...] a criatividade é o principal aspecto caracterizador do comportamento linguístico humano, aquilo que mais fundamentalmente distingue a linguagem humana dos sistemas de comunicação animal.”

Neste sentido, a criatividade humana no uso da língua implica diretamente no desenvolvimento evolutivo dela, ou seja, as línguas naturais passam por esse processo de criação e recriação, desde os primórdios da humanidade, e isso, também, ocorre com as línguas de sinais, pois os indivíduos surdos também são criativos, criando e recriando múltiplas possibilidades de uso da língua.

Desse modo, tendo em vista esse caráter evolutivo das línguas naturais, sobretudo das línguas de sinais, torna-se necessário traçar um escorço histórico do desenvolvimento da língua natural dos surdos, tanto em contexto europeu, quanto no âmbito nacional. $A$ priori, é conveniente fazer este levantamento da Língua Brasileira de Sinais, por ela possuir berço na Europa, especificamente, na França. Comprovando assim, a legitimidade evolutiva das Línguas de Sinais.

Diante dessa perspectiva, não se pode afirmar com precisão a data de criação da língua natural dos surdos, no entanto, vale salientar que para existir língua é necessário no mínimo dois falantes, e nesse caso dois surdos. Assim, diante dessa asserção, infere-se que a Língua de Sinais (LS) teria sua existência confirmada, desde que os surdos estejam socialmente organizados em uma comunidade. Conforme afirma Bakhtin (2009, p. 45) “[...] como sabemos, [a língua] resulta de um consenso entre indivíduos socialmente organizados no decorrer de um processo de interação.”.

Em relação aos registros referentes à data de criação das Línguas de Sinais, estes não apresentam precisão, ou seja, uma data específica que comprove a sua criança. Existem alguns relatos sobre a presença dos surdos em algumas culturas, que os envolvem em preconceito social e misticismo: preconceito no sentido de que o sujeito surdo era 


\section{Revista

visto como ser incapaz de aprender, e misticismo, porque algumas culturas os veneravam como seres especiais, e/ou ainda, como amaldiçoados pelos deuses. A exemplo, a grega e a egípcia.

No Egito antigo, os surdos eram considerados pessoas especialmente escolhidas. Seu silêncio e seu comportamento peculiar conferiam-lhes um ar de misticismo. Já na Grécia Antiga [...], o gosto estético dos gregos fazia que a feiura ou o desvio fosse visto com desprezo. Assim, todos os indivíduos que fossem de alguma forma, um peso para a sociedade eram exterminados. (PEREIRA et al, 2011, p. 05-06)

Diante dessa asserção, torna-se evidente os contrapontos sociais, que envolvem o desenvolvimento das línguas de sinais, e ainda, vale ratificar que esses mecanismos sociais de supremacia de indivíduos ouvintes sobre indivíduos surdos influenciaram, positivamente e negativamente, nos desdobramentos de métodos que possibilitaram a educação dos surdos.

Desse modo, torna-se percebível o poder hegemônico da sociedade ouvinte exercido sobre a minoria surda, isto é, o caráter da perfeição considerado como primordial aos indivíduos ouvintes se sobrepunha de forma preconceituosa sobre os surdos, tornandoos descapacitados para exercerem seu papel de cidadão perante a sociedade.

Nesse contexto, torna-se perceptível que: "Os ouvintes são acometidos pela crença de que ser ouvinte é melhor do que ser surdo, pois, na ótica ouvinte, ser surdo é o resultado da perda de uma habilidade 'disponível' para a maioria dos seres humanos”. (SALLES, 2004, p. 35). Logo, este preconceito fora construído socialmente disseminando-se por todas as camadas sociais, mas, vale salientar, que os mais afetados eram os indivíduos das camadas mais pobres.

É notório afirmar, que a nobreza detinha total controle da educação de seus filhos surdos, com a finalidade de manter a herança de seus bens na família. Neste caso, os 


\section{Revista

surdos eram educados por preceptores pagos, ou seja, professores particulares que com métodos próprios educavam os filhos dos nobres. Assim, pode-se perceber uma diferenciação de classes, enquanto os filhos surdos dos nobres aprendiam, aqueles das classes mais pobres eram excluídos da sociedade.

Entre os séculos XVI e XVIII, a educação das crianças surdas era planejada pela família. Para isso, eram contratados tutores com o objetivo de ensinar os surdos a se comunicar oralmente ou por escrito. Os métodos utilizados no ensino das crianças surdas eram muito semelhantes: os tutores usavam a fala, a escrita, o alfabeto manual e os sinais. (PEREIRA et al, 2011, p. 07).

Assim, um dos nomes que merece destaque na educação dos surdos seguindo métodos próprios que garantiam o aprendizado da língua oral e escrita da língua dos falantes, é o abade espanhol Pedro Ponce de Leon (1520-1584), que ganhou destaque na nobreza espanhola por ensinar a quatro surdos nobres a falar, e assim ter direito à herança. Segundo Pereira et al (2011) o método utilizado pelo abade era variável, ele fazia uso além da datilologia com as duas mãos, também, sinais desenvolvidos por monges beneditinos juntando-os aos sinais desenvolvidos pela família Velasco.

Este fato marca a educação numa perspectiva nunca antes pensada, a de educar o surdo, e possibilitar que ele se insira na sociedade, e mesmo que seja numa visão reducionista é um dos grandes marcos para a sociedade surda. Isto é, para se modelar socialmente e garantir o direito a sua herança, o surdo deveria falar. Mas, isto é apenas o início do desenvolvimento das filosofias educacionais para educação de surdos.

Segundo Lulkin (2000, p. 50) “[...] os interesses religiosos, econômicos e jurídicos eram os promotores de uma educação que precisava ser demonstrada perante uma 'oficialidade'”. Ou seja, a educação nessa perspectiva tinha como finalidade garantir a prosperidade da nobreza e ao mesmo tempo a da igreja, que recebia doações dos nobres. 


\section{Revista}

No entanto, torna-se necessário expor a hipótese de que “Alguns estudiosos cogitam a possibilidade de que a real intenção dessa aprendizagem fosse ensinar os surdos a ler a palavras de Deus [...]”. (BATISTA, 2012, p. 16). Isto é, torna-se evidente as intenções do abade em preparar os surdos para o processo de cristianização.

Nesta perspectiva, conforme afirma Lopes (2011, p. 43) “A surdez, [era] entendida como um problema de saúde, castigo ou algo a ser corrigido, era tratada de forma a minimizar seus efeitos aparentes, fazendo-se os sujeitos surdos falarem como se fossem ouvintes”.

A corrente filosófica educacional denominada Oralismo ${ }^{5}$ fora desenvolvida pelo alemão Heinick que defendia a ideia de que o surdo para estar em sociedade deveria oralizar, neste sentido, a principal finalidade do método oralista era colocar os indivíduos surdos em um patamar de "normalidade”, e para tanto, não importava como deveria ser feito, desde que o produto final no processo fosse a fala.

[...] antes de considerar que nada poderia ser feito pelos ouvidos 'mortos', ele tentou alguns procedimentos, inclusive, perfurou a membrana timpânica da orelha de um de seus alunos, fraturou o crânio de outro, sem falar nos pontos infeccionados atrás das orelhas de muitos. Suas ações eram, na verdade, tentativas de descobrir a causa da surdez, pois para ele os surdos educados por meio da Língua de Sinais eram sujeitos fracassados. (BATISTA, 2012, p. 20).

Neste sentido, de acordo com a autora, a posição dos defensores do Oralismo em relação à Língua de Sinais; desse ponto de vista, os surdos são considerados indivíduos inferiores. E, para torná-lo um sujeito habilitado e emancipado socialmente, utilizavam-se

${ }^{5}$ Do ponto de vista social, podemos considerar o Oralismo enquanto movimento de repressão do desenvolvimento da Identidade Surda, tendo em vista que a sua aplicação prima pela fala expressa oralmente. E enquanto filosofia educacional, o mesmo foi imposto de forma abusiva, contrapondo-se aos ideais propostos por L’Épee (Sinais Metódicos). O Oralismo perdurou por quase dois séculos, subjugando os surdos às arbitrariedades desse método. 


\section{Revista

práticas consideradas absurdas e antinaturais, como por exemplo, a tortura e o castigo, além das atitudes descritas por Batista (2012).

Diante dessa perspectiva, é notório evidenciar que a língua pode ser considerada como característica identitária de um povo, isto é, a identidade natural do surdo está marcada pelo uso de sua língua. Nesse sentido, forçá-lo a oralizar estaria diretamente ligado ao abandono de sua identidade. Dessa forma, “[...] a perda de identidade desses grupos está geralmente simbolizada pela perda da língua materna, em consequência de um processo de deslocamento linguístico na direção da língua dominante”. (KLEIMAN, 1998, p. 268).

As duas correntes filosóficas educacionais entram em divergência: a Língua de Sinais e o Oralismo disputam um mesmo espaço e fora necessário decidir qual seria o melhor método de desenvolvimento da aprendizagem pelos surdos, e para tanto se decidiu no Congresso de Milão ${ }^{6}$ de 1880 , que o Oralismo deveria ser obrigatório nas escolas de surdos.

Neste momento, a educação dos surdos sofre um retrocesso, pois os indivíduos inseridos em uma comunidade linguística diferente da dos ouvintes, não teriam a facilidade de desenvolver a fala. Segundo Goldfield (2010, p. 31) “O Oralismo dominou em todo o mundo até a década de 1970 [...]”, isto é, a imposição linguística perdurou quase um século sobre os surdos, depois do Congresso de Milão.

\footnotetext{
${ }^{6}$ Esse congresso aconteceu em 1880, na cidade de Milão, Itália. A partir do embate entre o método desenvolvido por L’Épee (Sinais Metódicos que privilegia a língua materna do surdo) e o Método criado por Heinick (Oralismo que privilegia a fala). O seu objetivo principal era debater qual desses métodos seria mais apropriado para o desenvolvimento da aprendizagem de indivíduos surdos. Assim, foram debatidos, do ponto de vista ouvinte, que a metodologia e bem como as técnicas relacionadas à aprendizagem do surdo deveriam pautar-se em modelos orais, como por exemplo, o método intuitivo (desenvolvimento da fala e posteriormente a escrita), e bem como o uso da leitura labial. Desse modo, prevaleceu as perspectiva oral para a Educação dos surdos.
} 


\section{Revista}

\section{EDUCAÇÃO, ARTES

VOLUME 9, NÚMERO 1, ANO 2014 ISSN 1984-3178

A década de 1970 marca o fim da escravidão dos surdos a essa filosofia, e também o início de novos rumos para esfera educacional, tendo em vista que nesse período fora criado uma nova corrente educativa para possibilitar a aprendizagem dos surdos. A ela fora denominada de Comunicação Total, por utilizar todos os recursos possíveis no processo comunicativo.

O que se colocava como argumento a favor da CT é que esta seria uma filosofia que não se oporia à diferença surda, mas que possibilitaria aos indivíduos acesso a várias formas de aprendizagem e de interlocução linguística, ou seja, os surdos aprenderiam não apenas o português, mas também a língua de sinais. (LOPES, 2011, 63).

Notadamente, a Comunicação Total se contrapunha as outras filosofias educacionais, pois, enquanto a Língua de Sinais primava pelo uso de recursos paralinguísticos, e o Oralismo privilegiava a fala, essa nova filosofia tinha como comprometimento a comunicação, ou seja, não importava de que modo o surdo interagisse desde que ele se comunicasse.

Assim, a História da criação das Línguas de Sinais está atrelada ao desenvolvimento de correntes filosóficas educacionais, sendo impossível dissociar essa simbiose. E ainda, é notório afirmar que algumas dessas filosofias primam pelo caráter identitário do surdo, no caso a Língua de Sinais, enquanto outras, como o Oralismo, subjuga o sujeito a um posicionamento radical e antinatural de que ele deve falar. Vale salientar ainda, que a efetivação das Línguas de Sinais como Língua, passara por grandes desafios até ser reconhecida linguisticamente e socialmente.

\subsection{E no Brasil, legalidade para a LIBRAS ${ }^{7}$}

${ }^{7}$ LIBRAS, constitui a sigla para denominar a Língua Brasileira de Sinais. E enquanto língua, possui regras próprias de construção, ou seja, toda língua natural parte de unidades mínimas, em sua composição lexical, para se chegar a unidades mais complexas, o item lexical. Assim, na LIBRAS as unidades básicas, 43 


\section{Revista}

\section{EDUCAÇÃO, ARTES E INCLUSÃO}

VOLUME 9, NÚMERO 1, ANO 2014

O contexto brasileiro em relação aos estudos e desenvolvimento das línguas de Sinais não difere de outros contextos, já apresentados inicialmente nesse trabalho. Podendo-se expor o panorama brasileiro a partir de 1855, marco inicial, historicamente, que se sucederam as primeiras abordagens da língua dos surdos. Isto implica afirmar, que anterior há esse ano, os surdos viviam na obscuridade social, e permaneceu assim, tendo em vista que a nobreza brasileira fora a primeira camada social a ter acesso à aprendizagem através da língua de sinais. Neste sentido, Goldfield (2010, p 32) afirma que:

Em relação ao Brasil, temos informações de que em 1855 chegou aqui o professor surdo francês Hernest Huet, trazido pelo imperador D. Pedro II, para iniciar um trabalho de educação de duas crianças surdas, com bolsas de estudo pagas pelo governo.

O autor diz que os surdos ensinados por Huet estudam com bolsas pagas pelo governo, no entanto algumas dúvidas ficam em evidência, pois, seria possível que eles fossem netos do imperador brasileiro. A história deixa essas lacunas que podem ser preenchidas pela sociedade.

Ainda em relação ao professor francês, vale salientar ainda, que Huet foi o patriarca da Língua de Sinais Brasileira, e marcou positivamente os avanças na educação dos surdos brasileiros, pois, ele fundou o Instituto Imperial Nacional de Surdos-mudos, que hoje é conhecido nacionalmente por INES/RJ (Instituto Nacional de Educação de Surdos), tendo sua sede localizada na cidade do Rio de Janeiro/RJ, e é o único do Brasil.

São perceptíveis as colaborações do francês Hernest Huet para a educação brasileira dos indivíduos surdos, no entanto, conforme ocorrera na Europa, o Brasil 


\section{Revista

também sofrera com a implementação obrigatória da Filosofia Oralista, tendo em vista que socialmente, não importa o país, o surdo fora considerado como uma ameaça social.

Notadamente, esses fatos marcam todo processo de construção de uma língua, que exibida pelas mãos fora vítima de preconceito social por não ser compreendida por aqueles que não a conhecem. Além disso, vale salientar que no Brasil, o Oralismo perdurou por cerca de uma década, e nesse período os surdos eram obrigados a falar, pois a língua de sinais era proibida.

E como marco histórico, de lutas e direitos de todo indivíduo surdo, e graças ao aprofundamento de estudos linguísticos, a Língua de Sinais foi reconhecida oficialmente, e hoje, ela é, legalmente, a Língua oficial dos surdos brasileiros. Tendo os surdos seus direitos linguísticos garantidos pela lei no 10. 436 de 24 de Abril de 2002. E também, o decreto de número 5.626, de 22 de dezembro de 2005, pelo qual O PRESIDENTE DA REPÚBLICA, no uso das atribuições que lhe confere o art. 84, inciso IV, da Constituição, e tendo em vista o disposto na Lei no 10.436, de 24 de abril de 2002, e no art. 18 da Lei no 10.098, de 19 de dezembro de 2000, prevê o reconhecimento da Línguas de Sinais previsto pela lei acima citada, e bem como a inclusão da LIBRAS como disciplina curricular, a formação do professor e do instrutor de LIBRAS. Além de estabelecer o acesso das pessoas surdas à educação através da Língua Brasileira de Sinais ${ }^{8}$

\footnotetext{
${ }^{8}$ Segundo Albres e Neves (2013, p. 96) "Na cidade do Rio de Janeiro, polo de emergência do movimento social surdo, Lucinda Ferreira Brito fez parte, ao lado de Eulalia Fernandes, da UERJ, e Tanya Amara Felipe, da UPE, da tríade de linguistas que marcou a configuração discursiva e as ações de importantes ativistas surdos no sentido da luta pelo reconhecimento da libras com base no seu estatuto de língua. No caso de Ferreira Brito e Fernandes, a interação com militantes do movimento surdo, deu-se primordialmente nas atividades acadêmicas desenvolvidas na UFRJ e na UERJ, respectivamente, sublinhando-se o fato de que Fernandes, a pedido da FENEIS, elaborou o parecer, atestando o caráter linguístico da língua de sinais utilizado pelos surdos brasileiros que embasou a justificação do projeto de lei que deu origem à lei de libras.”
} 


\section{Revista

No entanto, mesmo com meios legais para ser utilizada como ferramenta de comunicação, a Língua Brasileira de Sinais ainda é vítima dos preconceitos sociais, remanescente de nossos antepassados. Isto é, a atual sociedade tornou-se herdeira das mazelas sofridas pelo surdo no início da formação dessa língua. Esquecendo que a LS é maleável, há exemplo disso, o território brasileiro apresenta duas línguas de sinais: a LIBRAS, denominada a língua de sinais dos centros urbanos e a LSKB que é a Língua de Sinais Kaapor Brasileira, utilizada pelos índios da tribo Urubu-Kapoor.

Ainda vale ratificar que, igualmente à Europa, o Brasil passara pelas mesmas influências das filosofias no âmbito educacional, e o ponto mais sensível no que diz respeito à educação dos surdos, fora a escolha do método; enquanto o Oralismo aprisionara o surdo a fala, a LS possibilitava a sua libertação. Muitos foram os embates entre essas duas filosofias, mas um consenso deve ser estabelecido: o surdo tem total liberdade de escolha no método educativo, isto é, ele escolhe ser oralizado ou torna-se um usuário das Línguas de Sinais.

\section{LIBRAS E INCLUSÃO NO PROCESSO EDUCATIVO}

Em decorrência das profundas mudanças ocorridas na sociedade, principalmente no que se refere à aceitação dos indivíduos portadores de necessidades especiais, especificamente, dos surdos, hoje, a Educação abre um leque de possibilidades que permite a inserção desses indivíduos no processo educativo. Mas, vale salientar que isso não se constituiu uma tarefa fácil, e tão pouco, alcançou um nível de eficiência muito amplo.

O avanço do debate relativo à inclusão tem feito com que a temática tenha sido um dos eixos de análise contemporânea sobre os processos educacionais no final do século XX. A reformulação dos processos educativos mesmo se afirmando 


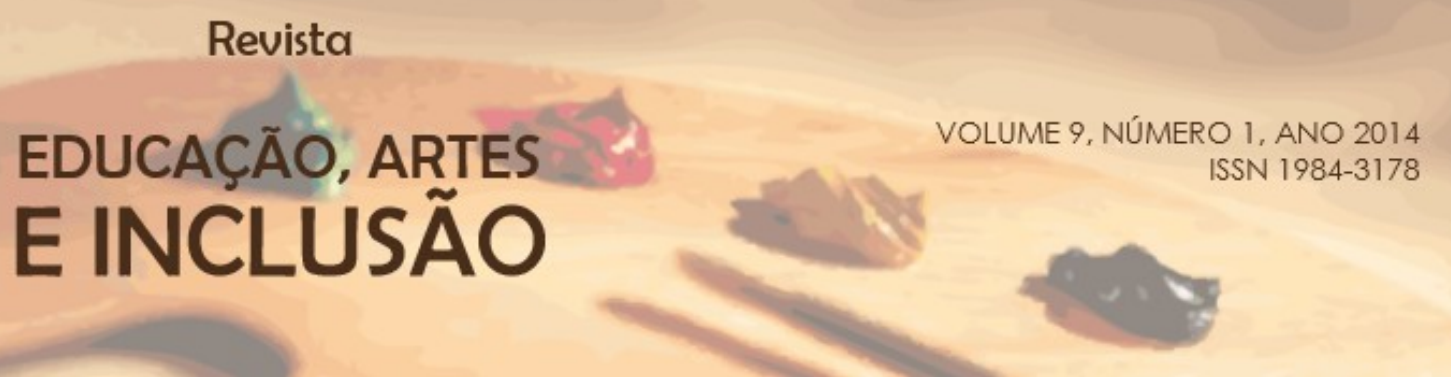

necessária, ainda é vista com resistência pela grande maioria dos educadores.

(FERREIRA, 2009, p. 1)

Essa resistência da qual fala Ferreira (2009) é inerente à sociedade, pois esses indivíduos, socialmente, sempre foram tratados com desprezo, como se fossem loucos, e até mesmo, incapazes de desenvolver sua capacidade cognitiva, ou seja, há todo um rótulo negativo construído em torno deles, principalmente, aquele que faz referência a deficiência. E, vale salientar, que esse lado negativo da surdez ${ }^{9}$ foi construído sob a perspectiva ouvinte. Mas, numa perspectiva intercultural, e levando em conta os traços comuns a determinados povos, como por exemplo, a língua, a surdez pode ser concebida como marca de identidade comum aos surdos, tendo em vista, que na grande maioria, todos apresentam traços de surdez. (STROBEL, 2009).

Desse modo, torna-se necessário rever as concepções que permeiam as bases da educação dos surdos, tendo em vista que o rótulo da deficiência perdurou durante séculos na sociedade, e que logicamente por estar imersa nesses valores, a Educação, de modo geral, também considerava esses indivíduos incapazes de desenvolver suas competências. Isto é, esse processo é influenciado por forças ideológicas externas que não acreditam na capacidade de aprendizagem dos indivíduos Surdos.

\footnotetext{
${ }^{9}$ A Surdez pode ser compreendida sobre duas perspectivas: a primeira delas faz referência a patologia, ou seja, biologicamente e esteticamente, o indivíduo surdo, apresenta uma deficiência no aparelho auditivo, logo, necessita de tratamento. Essa concepção de surdez, enquanto anormalidade, aludiu as bases da corrente Filosófica Educacional do Oralismo; A segundo concepção que se tem sobre surdez, faz referência a ela como marca característica de determinado indivíduo, e que esse está inserido em determinada comunidade, e assim, possui uma cultura. Vale salientar que essa concepção liga-se diretamente a corrente Filosófica Educacional do

Bilinguismo. Assim, "o jeito de o sujeito surdo entender o mundo e modificá-lo a fim de torná-lo acessível e habitável ajustando-o com suas percepções visuais, que contribuem para a definição das identidades surdas. [...] Isso significa que abrange a língua, as ideias, as crenças, os costumes e os hábitos do povo surdo. (STROBEL, 2009, p. 27).
} 


\section{Revista

Diante desse fato, a história atesta os movimentos ocorridos na sociedade pela mudança e reconstrução desse estereótipo socialmente construído, há exemplo o Deaf Power promovido pelos surdos americanos em 1988, mas que também influenciou os surdos brasileiros. Foram traçadas lutas pela obtenção de reconhecimento, e aceitação pela sociedade, de que o Surdo é capaz de desenvolver-se enquanto indivíduo e agir em sociedade, independentemente da sua surdez.

Assim, a partir desses movimentos, vive-se hoje a era da inclusão, ou seja, em decorrência das transformações sociais, provocada, também, por pesquisas científicas, a Educação enquanto sistema abre a oportunidade para que aqueles indivíduos deixem os patamares de exclusão, segregação, inserção e passem a ser inclusos, ao menos no sistema educativo.

Desse modo, a inclusão pode ser compreendida como um processo que se inicia desde conscientização de que todos têm direito à educação, independentemente das suas condições físicas, até a preparação dos profissionais que irão trabalhar com esse novo público.

\footnotetext{
A inclusão pode beneficiar não somente alunos que apresentem algum tipo de deficiência, mas alunos que não são 'enquadrados’ como deficientes, mas sofrem os efeitos de um processo de ensino-aprendizagem que ocasionam seu fracasso escolar, por exemplo. (MAGALHÃES et al, 2011, p. 22)
}

A partir das afirmações da autora, é percebível que se tem uma definição ampla para o termo incluir, e que esse ato possibilita a interação de todos, e assim quebrando todos os paradigmas, principalmente a do preconceito. No caso dos indivíduos Surdos, outra barreira a ser quebrada é a da comunicação, ou seja, para que os indivíduos possam estar inclusos, torna-se necessário que haja comunicação. 


\section{Revista

E ainda, apenas conhecer a Língua Brasileira de Sinais não é o suficiente para que a inclusão ocorra. Conforme afirma Vilhalda (s/d, p. 01)

Não é suficiente conhecer a Língua Brasileira de Sinais para poder atuar eficazmente na escola com o aluno Surdo. É também necessário conhecer a Cultura Surda através da participação e vivência na comunidade Surda, aceitação da diferença e paciência para inteirar-se nela.

Nessa perspectiva, a inclusão não pode se resumir somente ao ato de integrar um aluno surdo à comunidade escolar, desconhecendo todo seu contexto sócio-histórico que abarca as vivências desses indivíduos. Assim, conhecer e interagir diretamente na comunidade Surda, torna-se necessário para quebrar os próprios paradigmas do termo inclusão.

Além disso, o processo de inclusão está amparado em algumas leis, dentre elas pode se destacar: a Lei $\mathrm{N}^{\circ}$ 9.394, de 20 de dezembro de 1996, que estabelece as diretrizes e as bases da educação nacional. Pela qual, se estabelece a inclusão dos alunos com necessidades especiais, e neste caso, do ponto de vista da deficiência, o surdo.

Outra Lei preponderante ,para que de fato seja desenvolvida uma política de inclusão, é o reconhecimento da Língua Brasileira de Sinais-LIBRAS como uma língua da comunidade Surda, estabelecido e decretado pela Lei $N^{\circ}$ 10.436, de 24 de abril de 2002. Pela qual se reconhece oficialmente a maneira de se comunicar dos Surdos, ou seja, todo aparato linguístico utilizado na comunicação atribuem-se a uma língua.

Levando em consideração essa Lei, torna-se perceptível que para que haja, realmente, a inclusão dos indivíduos Surdos, é necessário que ela seja feita pela aceitação da LIBRAS como língua, isto é, comparada a outros sistemas comunicativos, como por exemplo a língua oral, ela segue basicamente a mesma regra geral: parte de unidades 


\section{Revista

mínimas, para criar unidades maiores, possibilitando assim, a comunicação. Desse modo, a inclusão dos Surdos no contexto escolar, ou em qualquer outro, se dará pela comunicação, e essa se efetiva pela Língua Materna deles.

Além do reconhecimento, torna-se necessário que os profissionais que trabalharão com os Surdos estejam preparados, ou seja, não é somente o reconhecimento de uma língua que a torna usual, mas, sua utilização em todos os contextos sóciocomunicativos. Desse modo, em sala de aula, para que seja quebrada a barreira da comunicação torna-se necessário que o professor conheça e utilize essa língua com proficiência. Nessa perspectiva, a inclusão dos alunos Surdos ocorrerá de fato.

Ainda numa perspectiva inclusiva, no que diz respeito à presença do surdo no processo de ensino e aprendizagem, convém, evidenciar os paradigmas da Educação Bilíngue $^{10}$, ou seja, em um patamar satisfatório de inclusão desse indivíduo deve possibilitar que o mesmo se desenvolva tanto na sua língua materna quanto na língua materna de seu país. Nesses patamares inclusivos, e numa perspectiva de maturação educativa, segundo Cialdine (2012, p. 15) “[...] a escola (professores e funcionários) deve estar preparada para adequar-se à realidade assumida e apresentar coerência diante do aluno e da família. É preciso disponibilizar ao aluno a aprendizagem da LIBRAS como, também, do português.”

É perceptível as contribuições do ensino numa perspectiva bilíngue, tendo em vista que desde o último congresso realizado pela Confederação Mundial de Surdos, em 1987, eles adquiriram direitos legais para se apropriarem da realidade através de um

\footnotetext{
${ }^{10}$ O bilinguismo ganhou força a partir das pesquisas na área das Línguas de Sinais. Neste cenário, na década de 60, vale destacar o pesquisador linguista William Stokoe, que em pesquisa percebeu a complexidade das estruturas linguísticas que compõem a LS, e nesse nível de complexidade linguística, o pesquisador equiparou a LS à qualquer outra língua oral. Desse modo, as pesquisas realizadas nessa área consolidaram uma nova corrente Filosófica para educação dos surdos, o Bilinguismo.
} 


\section{Revista

código linguístico próprio, ou seja, a aprendizagem, e aqui restringindo-a à escola, essa deverá ser realizada através da LIBRAS, tal qual exposto em lei, mencionado anteriormente. Assim, numa perspectiva bilíngue, é relevante que a aprendizagem leve em consideração a língua como marco cultural. Corroborando essa asserção, Cialdine (2012, p. 15) afirma que: “A escola [para surdos] deve contemplar temas relativos à cultura surda e uma disciplina de LIBRAS-, mas deve ser, ao mesmo tempo uma escola regular de ensino.”

Desse modo, o desenvolvimento de uma escola no nível do bilinguismo, numa perspectiva inclusiva do surdo, também, prima pela consolidação de uma cultura específica desse indivíduo, ou seja, o bilinguismo permite que a aprendizagem seja desenvolvida utilizando a língua materna do surdo, assim sendo, é através do reconhecimento dessa língua, que a mesma torna-se marca cultural. Nessa perspectiva, de inclusão do indivíduos surdos, espera-se que a educação bilíngue progrida significativamente, e que possibilite a transgressão do sistema educativa, no qual, em alguns casos, os surdos ainda vivenciam uma verdadeira desinclusão.

\section{CONSIDERAÇÕES}

A partir da presente pesquisa torna-se possível levantar algumas considerações. Sendo assim a primeira delas é que a partir dos contextos históricos analisados e estudados, percebeu-se que inicialmente a legitimação da Língua de Sinais passara por diversos entraves, dentre eles pode-se destacar o preconceito social sofrido pelos 


\section{Revista

indivíduos surdos, que de um ponto de vista estético eram vistos como pessoas incapazes de desenvolver-se enquanto cidadãos autônomos.

Vale salientar, que o pensamento da deficiência nesse contexto pode ser considerado o principal problema social para a inclusão do surdo enquanto indivíduo pertencente a uma sociedade. E, graças ao desenvolvimento de estratégias que possibilitassem a educação dos surdos, esse pensamento fora transformado em possibilidades positivas, mesmo que se tenham levados décadas para a difusão e propagação dessas possibilidades.

Dentre essas possibilidades de educação direcionadas ao surdo, foi possível evidenciar que a partir do século XV os primeiros modelos educacionais pensados para os surdos. Assim, têm-se os primeiros modelos de ensino baseados em alfabetos manuais, sinais básicos, e a escrita da língua oral, ou seja, esses primeiros passos dados ao desenvolvimento de uma educação para os surdos garantiram a elaboração de novos patamares educacionais.

Em conformidade com a vida social dos indivíduos surdos, foi notado também, o crescente interesse em desbravar a língua de sinais, e nesse caso, a criação dos Sinais Metódicos, pelo pesquisador L’Epee, garantiu ao surdo uma nova possibilidade de interação. Diante disso, foi percebido também, o desrespeito com os indivíduos surdos, com a criação do método Oralista que perdurou por cem anos como a melhor forma de se educar um surdo.

Ainda, com a presente pesquisa percebeu-se que os mesmo modelos educacionais desenvolvidos na Europa também se fizeram presente no Brasil, diferentemente, graças às lutas por obtenção do direito a uma língua que privilegiasse os aspectos característicos de seus usuários, a LIBRAS fora oficializada e reconhecida legalmente. 


\section{Revista}

\section{EDUCAÇÃO, ARTES E INCLUSÃO}

Assim, é evidente a importância dessa legalização, pois através de sua língua materna os surdos deixam de serem indivíduos descapacitados de um sistema linguístico, e passam a serem Surdos, sujeitos que utilizam uma língua baseada em sinais. E ainda, vale evidenciar que essa legalização, além de possibilitar o reconhecimento de uma nova língua, ainda torna-se um meio que possibilita a inclusão desses indivíduos.

Em detrimento do crescente avanço em pesquisas na área da língua de sinais, percebeu-se, também, que a inclusão do surdo no processo de ensino e aprendizagem apenas será possível a partir da adequação a Educação Regular ao sistema bilíngue, isto é, a implantação de uma política educacional bilíngue que privilegie tanto os aspectos linguísticos dessa língua quanto os artefatos culturais do sujeito surdo.

Desse modo, esse novo momento que a educação vem passando possibilita refletir sobre os critérios de inclusão estabelecidos para as instituições de ensino, ou seja, no caso da surdez é necessário que se desenvolva políticas educacionais que possibilitem, também, a utilização da LIBRAS por todos que fazem parte desse processo educativo. 


\section{Revista

\section{REFERENNCIAS}

ALBRES, N. A; NEVES, S. L. G. (orgs.) Libras em estudo: Política Linguística. São Paulo: FENEIS, 2013.

BAKHTIN, M. Marxismo e filosofia da linguagem: problemas fundamentais do método sociológico da linguagem. 13. ed. São Paulo: Hucitec, 2009.

CIALDINE, E. A história da educação (linguística) dos surdos. Revista Língua Portuguesa, conhecimento prático. № 31, 2012.

BATISTA, A. Q. D. O desenvolvimento da LIBRAS como língua natural e suas possíveis relações com a Língua Portuguesa. Monografia (Graduação em Letras) Universidade Estadual da Paraíba, Catolé do Rocha: UEPB, 2012.

FERREIRA, B. M. S. A LIBRAS na formação do professor: por uma Educação Inclusiva de Qualidade. Revista virtual de Cultura Surda e Diversidade. 4a ed. Junho/2009. Disponível em:< http://editora-arara-azul.com.br/novoeaa/revista/?p=149 >

GOLDFIELD, Márcia. A criança surda: linguagem e cognição numa perspectiva sociointeracionista. 3. ed. São Paulo: Plexus, 2010.

KLEIMAN, Ângela. A construção de identidade em sala de aula: um enfoque interacional. In: SIGNORINI, Inês (org.) Lingua(gem) e identidade: elementos para uma discussão no campo aplicado. Campinas, SP: Mercado das letras, 1998. 


\section{Revista

LOPES, Maura Corcini. Surdez \& Educação. Belo Horizonte: Autêntica Editora, 2011.

LULKIN, Sérgio. O silêncio disciplinado. A invenção dos surdos a partir de representações ouvintes. Dissertação (Mestrado em Educação) Faculdade de Educação, Programa de Pós-Graduação em Educação, Universidade Federal do Rio Grande do Sul, Porto Alegre: FACED/PPGEDU, 2000.

MAGALHÃES, R. C. B. P. Educação inclusiva: escolarização, política e formação docente. Brasília: Liber Livro, 2011.

MARTELOTTA, M. E. (org.). Manual de linguística. 2. ed. São Paulo: Contexto, 2011.

PEREIRA, M. C. C. (org.). LIBRAS: conhecimento além dos sinais. São Paulo: Pearson Prentice Hall, 2011.

QUADROS, Ronice Müller de \& KARNOPP, Lodenir Becker. Língua de Sinais Brasileira: estudos linguísticos. Porto Alegre: Artmed, 2004.

SALLES, H. M. M. L. (et al). Ensino de Língua portuguesa para surdos: caminhos para a prática pedagógica. Brasília: MEC, SEESP, 2004.

STROBEL, Karin. As imagens do outro sobre a cultura surda. 2. ed. rev. Florianópolis: Ed. da UFSC, 2009.

VILHALVA, S. Pedagogia Surda. Rio de Janeiro, Editora ARARA AZUL Ltda. Disponível em: < http://www.editora-arara-azul.com.br/pdf/artigo8.pdf > . Data de acesso: 03 de Junho de 2013. 